\title{
Desbuquois syndrome
}

INSERM

\section{Source}

INSERM. (1999). Orphanet: an online rare disease and orphan drug data base.

Desbuquois syndrome. ORPHA:1425

Desbuquois syndrome (DBQD) is an osteochondrodysplasia characterized by severe micromelic dwarfism, facial dysmorphism, joint laxity with multiple dislocations, vertebral and metaphyseal abnormalities and advanced carpotarsal ossification. Two forms have been distinguished on the basis of the presence (type 1) or the absence (type 2) of characteristic hand anomalies. A variant form of DBQD, Kim variant (see these terms), has also been described and is characterized by short stature and articular, minor facial and significant hand anomalies. 